\title{
The OPN Gene Polymorphism Confers the Susceptibility and Response to Ara-C Based Chemotherapy in Chinese AML Patients
}

\author{
Rong Zhang Wei Yang Ying Chun Li Guo Jun Zhang Kun Yao Rong Hu \\ Bin Wu \\ Department of Hematology, Shengjing Hospital of China Medical University, Shengjing City, China
}

\section{Key Words}

Osteopontin • Acute myeloid leukemia • Chemotherapy • Susceptibility • Polymorphism

\begin{abstract}
Aim: To investigate the possible association between the Osteopontin (OPN) gene polymorphisms and the susceptibility and chemotherapy response of acute myeloid leukemia patients. Methods: A total of 381 patients with de nova AML and 430 healthy controls were enrolled. All patients received Ara-C-based standard induction chemotherapy regimens, and the treatment response was evaluated. Several polymorphisms in the human OPN encoding gene have been identified. The OPN) gene polymorphisms at 3 loci, namely, $-156 \mathrm{GG}>\mathrm{G},-443$ C $>T$ and $-66 T>G$ were determined. Results: We identified that the $-443 C>T$ polymorphism was the only one which is closely related to AML. Compared with the -443TT carriers, our data showed that the $-443 C \mathrm{C}$ genotype carriers were significantly related to a higher risk for AML. The $-443 C C$ genotype was also more prevalent in poor response groups than in good response group. The $-443 C C$ carriers are more likely to have poor response to AML treatment. Cellular assay indicated that the leukemic cell lines receiving the OPN $-443 \mathrm{C}$ transfection have a significantly lower apoptosis rate to Ara-C treatment compared to cell lines transfected with $-443 T$. Conclusion: The findings of this study suggest OPN-443C $>$ T gene polymorphism may be sued as a molecular for susceptibility and chemotherapy response of AML.
\end{abstract}

Copyright $@ 2015$ S. Karger AG, Basel

\section{Introduction}

Acute myeloid leukemia is a heterogeneous clonal disorder characterized by the uncontrolled proliferation of neoplastic hematopoietic precursor cells that lose the ability to differentiate into mature cells $[1,2]$. The etiology of the disease is largely unknown. Currently, it is accepted that the environmental factors, including ionizing radiation, benzene 
exposure and cytotoxic chemotherapy play important role in the AML incidence $[3,4]$. In addition, the genetic factors are involved in the pathogenesis of AML $[5,6]$. Besides the fusion genes derived from chromosomal translocations, numerous gene mutations have also been reported in different types of AML. The genetic polymorphisms of several candidate genes have been reported to correlate to the susceptibility to AML in different ethnic populations $[7,8]$. Characterizing molecular mutations in AML is important for the management of patients individually.

Osteopontin (OPN) is a sibling glycoprotein that was first identified in osteoblasts [9]. As a multi-functional cytokine, OPN is involved in cell survival, migration and adhesion which is associated with tumorigenesis, progression and metastasis. OPN is also implicated in tumorgenesis and has been proposed as a cancer marker including nasopharyngeal carcinoma, lung cancer, colon cancer and prostate cancer [10,11].

The association between OPN and leukemia has also been reported. Adhesion to OPN in the bone marrow niche regulates lymphoblastic leukemia cell dormancy [12]. OPN increases the expression of $\beta 1$, 4-galactosyltransferase-I and promotes adhesion in human RL95-2 cells [13]. OPN also increases CD44 expression and prompts cell adhesion in RAW 264.7 murine leukemia cells [14]. Clinically, OPN is used as a prognostic factor for survival of AML patient [15].

Several polymorphisms in the human OPN encoding gene have been identified. The $-66 \mathrm{~T}>\mathrm{G}$ (rs28357094), -156G $>/ \mathrm{GG}$ ( $\mathrm{rs} 17524488)$, and $-443 \mathrm{C}>\mathrm{T}$ (rs11730582), polymorphisms among the most studied loci. The OPN gene polymorphism has been documented to be related to the susceptibility to cervical and thyroid cancers and their clinical features as well as prognosis $[16,17]$. To date, whether the OPN gene polymorphism affects the susceptibility to AML remains unknown. Base on the increased expression of OPN in the AML, we postulate there might be a positive association between the OPN gene polymorphism and AML incidence. Also we investigate if the OPN gene polymorphism affects the chemotherapy response in these patients.

\section{Materials and Methods}

A total of 381 patients with de nova AML without previous treatment were consecutively_enrolled in this study. The diagnosis of AML was performed according to clinical, morphological, cytochemical, and immunophenotypic examination. Among these patients with AML, 4 patients were diagnosed with minimally differentiated AML (M0); 38 patients for AML without maturation (M1); 130 AML with maturation (M2); 78 patients acute myelomonocytic leukemia (M4); 115 patients, acute monocytic leukemia (M5); 12 patients, erythroleukemia (M6); and 5 patients, acute megakaryoblastic leukemia (M7). The characteristics of the patients are shown in Table 1. The acute promyelocytic leukemia (M3) was excluded because of different treatment regimens. A total of 430 healthy subjects were enrolled as controls as well. Karyotype analysis showed that 172 had normal karyotype and 209 cases had karyotypic abnormalities: 46 had +8, 39 had-7/ del, 33 had +10, 12 had abn(11),4 had abn(17), 3 had abn (19), 41 had t(8,21) and 31 had high complex karyotype. The controls and AML patients were matched for age and gender. All participants were ethnically of Chinese Han. This study was approved by the Institute's Review Board and conducted according to the Helsinki declaration. The written consent was obtained from all patients and healthy controls and

\section{Evaluation of chemotherapy regimens and therapeutic response}

All patients received Ara-C-based standard induction chemotherapy regimens, and the treatment effects were evaluated after the second cycles of chemotherapy regimen. Patients receiving allogeneic stem cell transplantation were excluded from this study. A total of 115 patients received intravenous daunorubicin (DNR) $45 \mathrm{mg} \times \mathrm{m}-2 \times \mathrm{d}-1$ for $1-3$ days and Ara-C $100 \mathrm{mg} \times \mathrm{m}-2 \times \mathrm{d}-1$ for $1-7$ days (DA induction chemotherapy regimen); 167 patients received homoharringtonine (HHT) 3-4 mg $\times \mathrm{m}-2 \times \mathrm{d}-1$ for 5-7 days and Ara-C 100 $\mathrm{mg} \times \mathrm{m}-2 \times \mathrm{d}-1$ for $1-7$ days (HA induction chemotherapy regimen); and 99 patients received mitoxantrone 4 $\mathrm{mg} \times \mathrm{m}-2 \times \mathrm{d}-1$ for $1-5$ days and Ara-C $100 \mathrm{mg} \times \mathrm{m}-2 \times \mathrm{d}-1$ for $1-7$ days (MA induction chemotherapy regimen). Complete response (CR) was defined as follows: absolute values of granular leukocytes and platelets in 
peripheral blood are not more than $1.5^{\prime} 109 / \mathrm{L}$ and $100^{\prime} 109 / \mathrm{L}$ respectively; blast cell count in the bone marrow was less than $5 \%$ for at least 4 weeks and symptoms and signs of leukemia disappear; and granulopoiesis and megakaryocytopoiesis after chemotherapy with normalized peripheral blood counts persisting for at least 4 weeks, without intervening chemotherapy. Patients with other treatment response, including Partial remission, Non-remission and Early death were assigned as non-CR group [18].

OPN gene polymorphisms

DNA was extracted from peripheral whole blood using a Qiagen DNA Isolation Kit (Qiagen, Valencia, CA, USA). Three single nucleotide polymorphisms in the promoter region of OPN gene, including $-66 \mathrm{~T}>\mathrm{G}$ (rs28357094), -156G>/GG (rs17524488), and -443C>T (rs11730582), were determined using the TaqMan 5' allelic discrimination assay. It was performed using a commercially available kit Assays-on-DemandTM SNP genotyping products (Applied Biosystems, Foster City, CA). SNP amplification assays were used according to the manufacturer's instructions. In short, $10 \mathrm{ng}$ of sample DNA in $25 \mu \mathrm{L}$ of reaction solution containing 12.5 $\mu \mathrm{L}$ of the $2 \times$ TaqMan ${ }^{\circledR}$ Universal PCR Mix (Applied Biosystems), and $1.25 \mu$ l of pre-developed assay reagent from the SNP genotyping product containing two primers and two MCB-Taqman probes. Reaction condition was consisted of pre incubation at $50^{\circ} \mathrm{C}$ for $2 \mathrm{~min}$, at $95^{\circ} \mathrm{C}$ for $10 \mathrm{~min}$, followed by 40 cycles of $95^{\circ} \mathrm{C}$ for 15 $\mathrm{s}$ and $60^{\circ} \mathrm{C}$ for $1 \mathrm{~min}$. Amplifications were performed in an ABI Prism $\AA 7500$ Sequence Detection System (Applied Biosystems).

\section{Construction of luciferase reporter plasmids}

A 644/643 bp fragment from -645 to $-2 \mathrm{bp}$ of the OPN promoter was prepared by PCR amplification from genomic DNA of homozygous individuals for the four most common haplotypes (forward primer: 5'-ggggtaccTGAAGCAGCCCTCTCAAGCA-3'; reverse primer: 5'-gaagatctACAACCAAGCCCTCCCAGAAT-3'). DNA fragments containing different alleles of the human SPP1 gene from -645 to $-2\left(-155 \_156 \mathrm{G} /-443 \mathrm{~T}\right.$, -155_156G/-443C, -155_156GG/-443T and -155_156GG/-443C) were cloned into the pGL3 Basic Vector (Promega, Madison, WI, USA) between KpnI and BglII restriction sites, which were designated as A, B, C and D plasmids, respectively [19].

\section{Cell culture, transfection and luciferase assay}

Four leukemic cell lines, namely, KG1a,Kasumi-1, U937 and Thp-1 were cultured in a humidified incubator with $5 \% \mathrm{CO} 2$ at $37^{\circ} \mathrm{C}$. One day before transfection, the cells were cultured in a 96-well plate in $100 \mu \mathrm{l}$ culture medium without antibiotics to $90-95 \%$ confluence at the time of transfection. The cells were transfected using Lipofectamine 2000 Reagent according to the manufacturer's protocol (Invitrogen, Carlsbad, CA, USA). Briefly, $0.2 \mu \mathrm{g}$ of the pGL3 vector containing an OPN promoter fragment was used for each well. The transfection effect was $>90 \%$.

\section{Western Blotting Analysis}

Collected the transfected cells for western blot assay to detect OPN expression levels in these cells. Cells were lysed by RIPA Lysis Buffer. The protein concentration in the supernatant was determined with a BCA protein assay kit. The isolated protein $(15 \mu \mathrm{g})$ was separated by $10 \%$ SDS-PAGE and transferred onto polyvinylidene difluoride nylon membranes. The blots were probed with mouse anti-OPN, and anti-GAPDH antibody (1: 1000 dilution; Santa Cruz Biotechnology, Santa Cruz, USA). Then with horseradish peroxidaseconjugated secondary antibodies (1: 1000 dilution), and visualized using an ECL detection kit (Amersham Biosciences, Piscataway, NJ, USA).

Terminal Deoxynucleotidyl Transferase dUTP Nick End Labeling (TUNEL) Assay

The cell lines receiving different allele constructs transfections were treated with Ara-C at concentrations of $1.5 \mathrm{Um}$ for $24 \mathrm{~h}$. The apoptotic cells were detected by in situ DeadEndTM Colorimetric Apoptosis Detection System (Promega, Madison, WI) according to the manufacturer's instructions. Briefly, sample slides were washed in PBS and then fixed in $4 \%$ paraformaldehyde solution. Sections were incubated with terminal deoxynucleotidyl transferase enzyme in a humidified chamber at $37^{\circ} \mathrm{C}$ for $60 \mathrm{~min}$. The reaction was terminated by transferring the slides to $2 \times$ sodium citrate saline solution. The sections were counter stained with DAPI. For quantitative analyses, 5 fields per section were selected. Apoptosis was indexed by counting TUNEL positive cells per 100 nuclei per section.

\section{KARGER}


Table 1. The characteristics from AML patients and controls

\begin{tabular}{llll}
\hline Characteristic & Cases N=381 & Controls N =430 & P value \\
\hline Sex & & & \\
Male & 197 & 224 & 0.484 \\
Female & 184 & 206 & \\
Age (years) & $54.5 \pm 3.6$ & $54.6 \pm 4.1$ & 0.763 \\
Smoke status & & & $<0.001$ \\
never & 56 & 146 & \\
ever smoker & 146 & 143 & \\
current & 179 & 141 & \\
\hline
\end{tabular}

Statistical Analysis

Deviations from Hardy-Weinberg equilibrium (HWE) for genotypes were assessed by $\chi 2$-test. Demographic and clinical information was compared to genotype, using $\chi 2$-test or Fisher's exact test. The significant difference of genotypes in different responders was calculated using $\chi 2$ test. We estimated the risk for AML as odds ratio (ORs) and 95\% confidence intervals (CIs). The OR and 95\% CI were calculated by Logistic regression analysis with adjustment of clinical variables. All statistical tests for this analysis were performed using SPSS 17.0 software (SPSS Inc., USA). P values lower than 0.05 were considered statistically significant.

\section{Results}

The characteristics from patients are presented in Table 1. There was no significant difference in age and sex between AML cases and controls (all P > 0.05). The AML patients have higher percentage of smokers than controls $(\mathrm{P}<0.001)$.

Table 2 describes the genotype and allele distributions of OPN gene polymorphisms in the AML and control groups. The genotype frequencies for all polymorphisms did not differ significantly from those expected under Hardy-Weinberg equilibrium (all $\mathrm{P}>0.05$ ). For the $-443 \mathrm{C}>\mathrm{T}$ polymorphism, AML patients had a higher prevalence of CC genotype than the controls $(30.71 \%$ vs. $20.93 \%$, global $\mathrm{P}<0.001)$. We performed the univariate and multivariate logistic regression analysis with the adjustment of age, sex, smoking status, white blood cells, hemoglobin and platelet numbers. Compared with the -443TT carriers, our data showed that the -443CC genotype carriers were significantly related to a higher risk for AML (adjust $\mathrm{OR}=1.98,95 \% \mathrm{CI}: 1.45-2.89$ adjusted $\mathrm{P}=0.002$ ). The $-443 \mathrm{C}$ allele carriage is associated with higher risk for AML (adjust $\mathrm{OR}=1.44,95 \% \mathrm{CI}$ : 1.05-1.52 adjusted $\mathrm{P}=0.015$ ). In contrast, the genotype distribution of $-156 \mathrm{G}>\mathrm{GG}$ and $-66 \mathrm{G}>\mathrm{T}$ were not significantly different between the AML and control groups (both $\mathrm{P}>0.05$ ). The allelic frequencies in -66T/-66G and -156G/156GG were not similar between AML patients and healthy controls. The logistic regression analysis did reveal the association of genotype and allele distributions of -156G>GG and $-66 \mathrm{G}>\mathrm{T}$ with the incidence of AML (Table 2).

The mean serum OPN levels were compared according to the OPN genotypes. We found that the $-443 \mathrm{CC}$ carriers had a significantly higher serum OPN than CT and TT carriers $(194 \pm 12$ vs.129 \pm 21 and $114 \pm 13, \mathrm{ng} / \mathrm{ml}, \mathrm{P}<0.001)$. The gene polymorphisms at other $-156 \mathrm{G}>\mathrm{GG}$ and $-66 \mathrm{G}>\mathrm{T}$ did not affect the thrombin-cleaved OPN levels.

We next stratified all patients and controls by age ( $<60$ years old and $>=60$ years old). We found that the $-443 \mathrm{C}$ allele carriage is still associated with higher risk for AML (adjust $\mathrm{OR}=1.95,95 \% \mathrm{CI}: 1.12-3.40$, adjusted $\mathrm{P}=0.018$ ) in $<60$ group and $>=60$ group (Table 3 ).

Table 4 showed the frequencies of genotypes in different treatment response in AML patients, and the association of OPN genotypes with the treatment response status. The -443CC genotype was more prevalent in non-CR groups than in CR group. After adjusting with clinical variables including age, sex, smoking status, white blood cells, hemoglobin and platelet numbers and distribution of chemotherapy agents, the multiple regression analyses revealed that the $-443 \mathrm{CC}$ carriers are more likely to have poor response to AML treatment (adjusted OR=2.09, $\mathrm{p}=0.023$, Table 3). For other loci of OPN gene, the genotypes were not 
Table 2. The genotype and allele distributions of OPN gene polymorphisms in AML and control groups

\begin{tabular}{llllllllll}
\hline & & AML & $\%$ & $\begin{array}{l}\text { Control } \\
\text { N=430 }\end{array}$ & $\%$ & $\begin{array}{l}\text { adjusted } \\
\text { OR }\end{array}$ & $95 \%$ CI & & $\begin{array}{l}\text { adjusted } \\
\text { P }\end{array}$ \\
& & & & & & & & \\
\hline$-66 \mathrm{~T}>$ G & TT & 89 & $23.36 \%$ & 99 & $23.02 \%$ & 1.00 & & & \\
& TG & 199 & $52.23 \%$ & 210 & $48.84 \%$ & 1.05 & 0.75 & 1.49 & 0.765 \\
& GG & 93 & $24.41 \%$ & 121 & $28.14 \%$ & 0.85 & 0.58 & 1.27 & 0.435 \\
& T & 377 & $49.48 \%$ & 543 & $51.03 \%$ & 1.00 & & & \\
& G & 385 & $50.52 \%$ & 521 & $48.97 \%$ & 1.06 & 0.88 & 1.28 & 0.511 \\
$-443 \mathrm{C}>\mathrm{T}$ & TT & 81 & $21.26 \%$ & 117 & $27.21 \%$ & 1.00 & & & \\
& CT & 183 & $48.03 \%$ & 223 & $51.86 \%$ & 1.19 & 0.84 & 1.67 & 0.333 \\
& CC & 117 & $30.71 \%$ & 90 & $20.93 \%$ & 1.98 & 1.45 & 2.89 & 0.002 \\
& T & 345 & $45.28 \%$ & 543 & $51.03 \%$ & 1.00 & & & \\
$-156 G>$ GG & C & 417 & $54.72 \%$ & 521 & $48.97 \%$ & 1.44 & 1.05 & 1.52 & 0.015 \\
& GG & 84 & $22.05 \%$ & 114 & $26.51 \%$ & 1.00 & & & \\
& GGG & 198 & $51.97 \%$ & 226 & $52.56 \%$ & 1.19 & 0.85 & 1.67 & 0.319 \\
& GGGG & 99 & $25.98 \%$ & 90 & $20.93 \%$ & 1.49 & 1.00 & 2.23 & 0.050 \\
& G & 366 & $48.03 \%$ & 543 & $51.03 \%$ & 1.00 & & & \\
& GG & 396 & $51.97 \%$ & 521 & $48.97 \%$ & 1.13 & 0.94 & 1.36 & 0.206 \\
\hline
\end{tabular}

Table 3. The genotype and allele distributions of OPN gene polymorphisms in AML and control groups stratified by age

\begin{tabular}{lcccccccccc}
\hline Age & Genotype & & AML & & Control & & $\begin{array}{l}\text { adjusted } \\
\text { OR }\end{array}$ & 95\%CI & $\begin{array}{l}\text { adjusted } \\
\text { P }\end{array}$ \\
\hline$<60$ & $-443 \mathrm{C}>\mathrm{T}$ & TT & 40 & $21.39 \%$ & 58 & $28.29 \%$ & 1.00 & & \\
& & CT & 91 & $48.66 \%$ & 102 & $49.76 \%$ & 1.29 & 0.79 & 2.12 & 0.305 \\
& & CC & 56 & $29.95 \%$ & 45 & $21.95 \%$ & 1.80 & 1.03 & 3.17 & 0.039 \\
& & T & 171 & $45.72 \%$ & 218 & $53.17 \%$ & 1.00 & & & \\
$>=60$ & $-443 \mathrm{C}>\mathrm{T}$ & C & 203 & $54.28 \%$ & 192 & $46.83 \%$ & 1.35 & 1.02 & 1.79 & 0.037 \\
& & TT & 41 & $21.13 \%$ & 59 & $26.22 \%$ & 1.00 & & & \\
& & CT & 92 & $47.42 \%$ & 121 & $53.78 \%$ & 1.09 & 0.68 & 1.77 & 0.714 \\
& CC & 61 & $31.44 \%$ & 45 & $20.00 \%$ & 1.95 & 1.12 & 3.40 & 0.018 \\
& & T & 174 & $44.85 \%$ & 239 & $53.11 \%$ & 1.00 & & & \\
& & C & 214 & $55.15 \%$ & 211 & $46.89 \%$ & 1.39 & 1.06 & 1.83 & 0.017 \\
\hline
\end{tabular}

Table 4. The frequencies of genotypes of $-443 \mathrm{C}>\mathrm{T}$ genotype in treatment response to patients with AML

\begin{tabular}{lccccccccc}
\hline & & Non-CR & $\%$ & CR & $\%$ & $\begin{array}{l}\text { adjusted } \\
\text { OR }\end{array}$ & $95 \%$ CI & \multicolumn{2}{c}{$\begin{array}{l}\text { adjusted } \\
\text { P }\end{array}$} \\
\hline$-443 \mathrm{C}>\mathrm{T}$ & TT & 43 & $23.24 \%$ & 54 & $27.55 \%$ & 1.00 & & & \\
& CT & 82 & $44.32 \%$ & 104 & $53.06 \%$ & 0.99 & 0.60 & 1.62 & 0.969 \\
& CC & 60 & $32.43 \%$ & 38 & $19.39 \%$ & 1.98 & 1.12 & 3.51 & 0.018 \\
T & 168 & $45.41 \%$ & 212 & $54.08 \%$ & 1.00 & & & \\
C & 202 & $54.59 \%$ & 180 & $45.92 \%$ & 1.42 & 1.06 & 1.88 & 0.017 \\
\hline
\end{tabular}

substantially different between good response and poor response groups (data not shown).

By using the Dual Luciferase Reporter Assay System we compared the promoter activity of leukemia cell lines transfected with different OPN gene alleles. We found a significant difference between cells transfected with the $-443 \mathrm{C}$ and $-443 \mathrm{~T}$ alleles. As shown in Figure 1a, significantly higher luciferase activities were observed with the pGL3-C construct compared to the pGL3-T construct (all $\mathrm{P}<0.001$ in 4 cell lines). As expected, Figure $1 \mathrm{~b}$ shows that the $-443 \mathrm{C}$ construct transfection induced significantly higher OPN protein expressions in all tested leukemic cell lines.

The cell lines receiving different allele constructs transfections were treated with Ara-C, followed by TUNEL assay to evaluate the cellular apoptosis levels. Cellular assay indicated that only the $-443 \mathrm{C}$ and $-443 \mathrm{~T}$ transfection significantly affect the proliferation and apoptosis rates of leukemic cell lines induced by Ara-C. The leukemic cell lines receiving the OPN -443C transfection have a lower apoptosis rate to Ara-C treatment compared to cell lines transfected with $-443 \mathrm{~T}$. Figure 2 shows the quantitative analyses of the apoptosis rates in the studied cell lines. 
Fig. 1. a) The OPN gene promoter activities and OPN protein expression in cultured leukemia cell lines transfected with pGL3-T and pGL3-C construct. The $-443 \mathrm{C}$ construct transfection induced significantly higher promoter activities in all tested leukemic cell lines ( $\dagger, \mathrm{P}<0.001$, vs. $-443 \mathrm{~T})$. b) The $-443 \mathrm{C}$ construct transfection induced significantly higher OPN protein expessions in all tested leukemic cell lines.

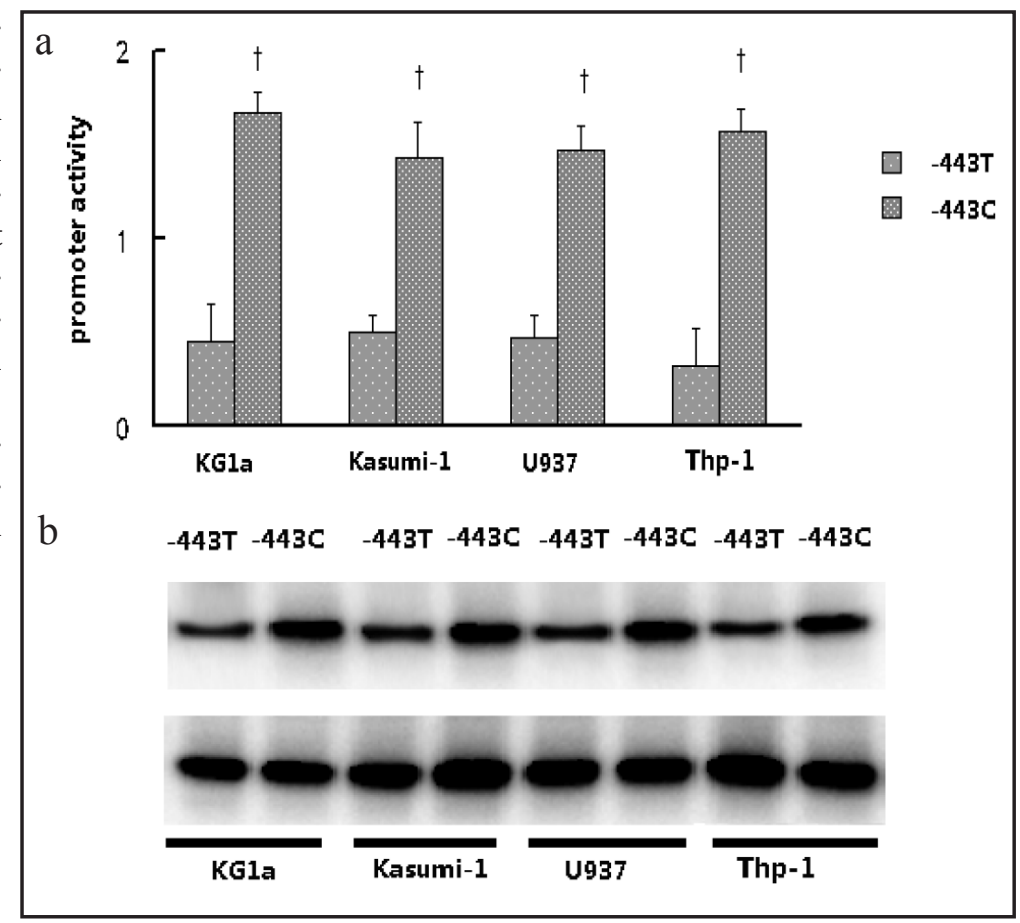

Fig. 2. The quantitative analyses of the apoptosis rates in cell lines transfected transfected with pGL3-T and pGL3-C construct. The $-443 \mathrm{C}$ construct transfection increased the resistance of leukemic cell lines to Ara-C treatment, indicated by significantly reduced apoptosis rates $(\dagger, \mathrm{P}<0.001$, vs. -443T).

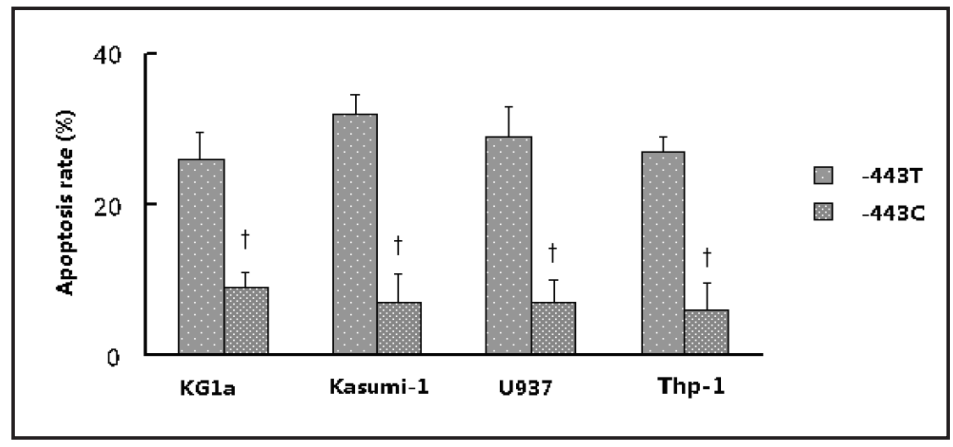

\section{Discussion}

In the present study, we reported the association between OPN gene polymorphism and AML in Chinese patients. We identified that the $-443 \mathrm{C}>\mathrm{T}$ polymorphism was the only one which is closely related to AML. Compared with the -443TT carriers, our data showed that the -443CC genotype carriers were significantly related to a higher risk for AML. The -443CC genotype was also more prevalent in poor response groups than in good response group. The -443CC carriers are more likely to have poor response to AML treatment. Cellular assay indicated that the leukemic cell lines receiving the OPN -443C transfection have a significantly lower apoptosis rate to Ara-C treatment compared to cell lines transfected with $-443 \mathrm{~T}$. To the best of our knowledge, this is the first study regarding the close association between OPN443C $>$ T gene polymorphism and the susceptibility and chemotherapy response of AML.

Osteopontin (OPN) is a secreted glycoprotein of the SIBLING family that is involved in physiologic and pathophysiologic processes. The association between OPN and solid cancers has been reported in hepatocellular carcinoma, pancreatic Cancer and lung cancer [20-22]. Increased serum OPN concentrations occur in chronic myeloid leukemia, multiple myeloma, and acute myeloid leukemia [23]. Higher OPN were associated with significant shorter survival times in AML patients in a 1-year survival analysis [24].

The OPN gene polymorphism has been documented to be related to risk, clinical feature and prognosis of a variety of cancers. For example, the cervical cancer patients had 
markedly higher percentage of -156 GG carriage and significantly lower TT and TC of -443 genotypes than controls [17]. Variation at -443 in the OPN promoter increases the potential for gastric cancermetastasis and subsequent death in the Chinese population [25]. In that study, the authors measured the promoter activity of the $-443 \mathrm{~T}>\mathrm{C}$ polymorphism using a dual luciferase reporter assay. Significantly higher luciferase activities were observed in the pGL3-C construct compared to the pGL3-T construct [25]. In gliomas patients, those patients with -443CC genotype had a poorer prognosis than those with -443TT and -443CT genotypes [26]. OPN $-443 \mathrm{C}>\mathrm{T}$ gene polymorphism may be used as a molecular marker to predict the treatment response to chemotherapy in advanced lung cancer patients [27]. OPN plays a crucial role in hepatocellular carcinoma (HCC) metastasis. The genetic variation at locus -443 of the OPN promoter plays important roles in the regulation of OPN expression and cancerprogression of HCCs [28]. In this study, we found that the $-443 \mathrm{C}>\mathrm{T}$ OPN443C $>\mathrm{T}$ gene polymorphism and the susceptibility and chemotherapy response of AML. This is consistent with most of the published studies. A recent study shows that AML patients expressing high levels of OPN within the bone marrow experienced shortened overall survival [15] . The -443CC carriers had significantly higher OPN than CT and TT carriers. We thus postulate the OPN gene polymorphism affect the risk and prognosis or AML patients via regulation of OPN protein levels.

The association between the $\mathrm{OPN}-443 \mathrm{C}>\mathrm{T}$ gene polymorphism and the chemotherapy response is another novelty of this study. To date, only a few studies reported OPN gene polymorphism as a marker predicting the efficacy of interferon-based therapies in patients with chronic hepatitis C [29], but no study reported the OPN gene polymorphism and the chemotherapy response in cancer. In this study, we found that $-443 \mathrm{CC}$, not only increases the AML risk , but also make its carriers more resistant to chemotherapy. This observation is supported by our in vitro study. We found that the leukemic cell lines receiving the OPN $-443 \mathrm{C}$ transfection have a significantly lower apoptosis rate to Ara-C treatment compared to cell lines transfected with $-443 \mathrm{~T}$. We postulate the $\mathrm{OPN}-443 \mathrm{C}>\mathrm{T}$ gene polymorphism may influence the transcript activity and affect the OPN expression level, thus change the cellular response to Ara-C induced apoptosis.

In this study, we observe a higher smoking rate among AML patients compared with healthy controls. Previous cohort and case-control studies have suggested that cigarette smoking may be involved in the etiology of leukemia in many populations [3032]. Cigarette smoke has also been linked to adult myeloid leukemia. Exposure to paternal preconception smoking alone or in combination with postnatal passive smoking increases the risk of childhood leukemia [33]. To investigate the effect of gene-environment interactions to incidence of myeloid leukemia, Vineis et al. selected several candidate polymorphisms in genes coding for enzymes involved in biotransformation of environmental toxicants and found that in people exposed to high levels of environmental tobacco smoke, the studied genetic genotype (GSTM1, GSTT1, SULT 1A1) was associated with an increased risk of leukemia [34]. In this study, we involved the smoking status in the univariate and multivariate logistic regression analysis to see if the higher AML prevalence rate with certain polymorphism is associated with smoking incidence. Our data showed that the -443CC genotype carriers were significantly related to a higher risk for AML (adjust OR=1.98, 95\%CI: 1.45-2.89 adjusted $\mathrm{P}=0.002$ ). However, smoking itself is not a independent risk factor for incidence of AML in our study.

Several limitations in this study need to be addressed. This study was a single-center cohort investigation and the sample size is relatively small. In addition, all the participants of this study were Chinese. Thus, the association between OPN gene polymorphism and AML needs to be further tested in different ethical populations with larger sample size. Secondly, a recent study shows that AML patients expressing high levels of OPN within the bone marrow experienced shortened overall survival [15]. We did not provide the prognostic data of OPN gene polymorphism on AML patients. 
Zhang et al.: OPN Gene Polymorphism and Chemotherapy Response in AML

\section{References}

1 Mlak R, Krawczyk P, Ramlau R, Kalinka-Warzocha E, Wasylecka-Morawiec M, Wojas-Krawczyk K, Kucharczyk T, Homa I, Koziol P, Ciesielka M, Chudziak D, Milanowski J: Predictive value of ercc1 and rrm1 gene single-nucleotide polymorphisms for first-line platinum- and gemcitabine-based chemotherapy in non-small cell lung cancer patients. Oncol Rep 2013;30:2385-2398.

2 Marchesi F, Annibali O, Cerchiara E, Tirindelli MC, Avvisati G: Cytogenetic abnormalities in adult nonpromyelocytic acute myeloid leukemia: A concise review. Crit Rev Oncol Hematol 2011;80:331-346.

-3 O'Donnell MR: Risk stratification and emerging treatment strategies in acute myeloid leukemia. J Natl Compr Canc Netw 2013;11:667-669.

-4 Morton LM, Dores GM, Tucker MA, Kim CJ, Onel K, Gilbert ES, Fraumeni JF, Jr., Curtis RE: Evolving risk of therapy-related acute myeloid leukemia following cancer chemotherapy among adults in the united states, 1975-2008. Blood 2013;121:2996-3004.

5 Al-Bahar S, Adriana Z, Pandita R: Acute myeloid leukemia as a genetic disease. Review article. Gulf J Oncolog 2008:9-15.

6 Naoe T, Kiyoi H: Gene mutations of acute myeloid leukemia in the genome era. Int J Hematol 2013;97:165174.

7 Moon JH, Sohn SK, Lee MH, Jang JH, Kim K, Jung CW, Kim DH: Bcl2 gene polymorphism could predict the treatment outcomes in acute myeloid leukemia patients. Leuk Res 2010;34:166-172.

8 Wrobel T, Gebura K, Wysoczanska B, Jazwiec B, Dobrzynska O, Mazur G, Kuliczkowski K, Bogunia-Kubik $\mathrm{K}$ : Il-17f gene polymorphism is associated with susceptibility to acute myeloid leukemia. J Cancer Res Clin Oncol 2014

-9 Inoue M, Shinohara ML: Intracellular osteopontin (iopn) and immunity. Immunol Res 2011;49:160-172.

10 Weber GF, Lett GS, Haubein NC: Categorical meta-analysis of osteopontin as a clinical cancer marker. Oncol Rep 2011;25:433-441.

11 Wang HH, Wang XW, Tang CE: Osteopontin expression in nasopharyngeal carcinoma: Its relevance to the clinical stage of the disease. J Cancer Res Ther 2011;7:138-142.

12 Boyerinas B, Zafrir M, Yesilkanal AE, Price TT, Hyjek EM, Sipkins DA: Adhesion to osteopontin in the bone marrow niche regulates lymphoblastic leukemia cell dormancy. Blood 2013;121:4821-4831.

13 Zhu F, Shen F, Fan Y, Xie Y, Xia Y, Kong Y: Osteopontin increases the expression of beta1, 4-galactosyltransferase-i and promotes adhesion in human rl95-2 cells. Glycoconj J 2012;29:347-356.

14 Marroquin CE, Downey L, Guo H, Kuo PC: Osteopontin increases cd44 expression and cell adhesion in raw 264.7 murine leukemia cells. Immunol Lett 2004;95:109-112.

15 Liersch R, Gerss J, Schliemann C, Bayer M, Schwoppe C, Biermann C, Appelmann I, Kessler T, Lowenberg B, Buchner T, Hiddemann W, Muller-Tidow C, Berdel WE, Mesters R: Osteopontin is a prognostic factor for survival of acute myeloid leukemia patients. Blood 2012;119:5215-5220.

$16 \mathrm{Mu}$ G, Wang H, Cai Z, Ji H: Opn -443c>t genetic polymorphism and tumor opn expression are associated with the risk and clinical features of papillary thyroid cancer in a chinese cohort. Cell Physiol Biochem 2013;32:171-179.

-17 Xu Q, Yuan B, Xue F, Zhang L, Li J, Guo H, Yue T: Opn gene polymorphisms are associated with susceptibility and clinicopatholigical characteristics of cervical cancer in a chinese cohort. Cancer Biomark 2011;10:233239.

18 Xu PP, Chen BA, Feng JF, Cheng L, Xia GH, Li YF, Qian J, Ding JH, Lu ZH, Wang XM, Xu K, Schultz M: Association of polymorphisms of cytosine arabinoside-metabolizing enzyme gene with therapeutic efficacy for acute myeloid leukemia. Chin Med J (Engl) 2012;125:2137-2143.

19 Chen J, Wu Q Lu Y, Xu T, Huang Y, Ribas J, Ni X, Hu G, Huang F, Zhou L, Lu D: Spp1 promoter polymorphisms and glioma risk in a chinese han population. J Hum Genet 2010;55:456-461.

20 Nogueira da Costa A, Plymoth A, Santos-Silva D, Ortiz-Cuaran S, Camey S, Guilloreau P, Sangrajrang S, Khuhaprema T, Mendy M, Lesi OA, Chang HK, Oh JK, Lee DH, Shin HR, Kirk GD, Merle P, Beretta L, Hainaut P: Osteopontin and latent-tgf beta binding-protein 2 as potential diagnostic markers for hbv-related hepatocellular carcinoma. Int J Cancer 2014

21 Saxena S, Gandhi A, Lim PW, Relles D, Sarosiek K, Kang C, Chipitsyna G, Sendecki J, Yeo CJ, Arafat HA: Ran gtpase and osteopontin in pancreatic cancer. Pancreat Disord Ther 2013;3:113. 


\section{Cellular Physiology Cell Physiol Biochem 2015;35:175-183 and Biochemistry \\ Zhang et al.: OPN Gene Polymorphism and Chemotherapy Response in AML}

-22 Yu TT, Han ZG, Shan L, Tao J, Zhang T, Yuan SF, Shen HL: Expression of osteopontin in non-small cell lung cancer and correlative relation with microvascular density. Asian Pac J Cancer Prev 2014;15:29-32.

-23 Saeki Y, Mima T, Ishii T, Ogata A, Kobayashi H, Ohshima S, Ishida T, Tabunoki Y, Kitayama H, Mizuki M, Katada Y, Asaoku H, Kitano M, Nishimoto N, Yoshizaki K, Maeda M, Kon S, Kinoshita N, Uede T, Kawase I: Enhanced production of osteopontin in multiple myeloma: Clinical and pathogenic implications. $\mathrm{Br} \mathrm{J}$ Haematol 2003;123:263-270.

-24 Wai PY, Kuo PC: Osteopontin: Regulation in tumor metastasis. Cancer Metastasis Rev 2008;27:103-118.

25 Zhao F, Chen X, Meng T, Hao B, Zhang Z, Zhang G: Genetic polymorphisms in the osteopontin promoter increases the risk of distance metastasis and death in chinese patients with gastric cancer. BMC Cancer 2012;12:477.

26 Shen Z, Chen B, Hou X, Chen P, Zhao G, Fan J: Polymorphism -433 c>t of the osteopontin gene is associated with the susceptibility to develop gliomas and their prognosis in a chinese cohort. Cell Physiol Biochem 2014;34:1190-1198.

27 Hao Y, Liu J, Wang P, Wang F, Yu Z, Li M, Chen S, Ning F: Opn polymorphism is related to the chemotherapy response and prognosis in advanced nsclc. Int J Genomics 2014;2014:846142.

28 Dong QZ, Zhang XF, Zhao Y, Jia HL, Zhou HJ, Dai C, Sun HJ, Qin Y, Zhang WD, Ren N, Ye QH, Qin LX: Osteopontin promoter polymorphisms at locus -443 significantly affect the metastasis and prognosis of human hepatocellular carcinoma. Hepatology 2013;57:1024-1034.

29 Naito M, Matsui A, Inao M, Nagoshi S, Nagano M, Ito N, Egashira T, Hashimoto M, Mishiro S, Mochida S, Fujiwara K: Snps in the promoter region of the osteopontin gene as a marker predicting the efficacy of interferon-based therapies in patients with chronic hepatitis c. J Gastroenterol 2005;40:381-388.

-30 Farioli A, Legittimo P, Mattioli S, Miligi L, Benvenuti A, Ranucci A, Salvan A, Rondelli R, Conter V, Magnani C: Tobacco smoke and risk of childhood acute lymphoblastic leukemia: Findings from the setil case-control study. Cancer Causes Control 2014;25:683-692.

-31 Kasim K, Levallois P, Abdous B, Auger P, Johnson KC: Environmental tobacco smoke and risk of adult leukemia. Epidemiology 2005;16:672-680.

-32 Metayer C, Zhang L, Wiemels JL, Bartley K, Schiffman J, Ma X, Aldrich MC, Chang JS, Selvin S, Fu CH, Ducore J, Smith MT, Buffler PA: Tobacco smoke exposure and the risk of childhood acute lymphoblastic and myeloid leukemias by cytogenetic subtype. Cancer Epidemiol Biomarkers Prev 2013;22:1600-1611.

-33 Chang JS, Selvin S, Metayer C, Crouse V, Golembesky A, Buffler PA: Parental smoking and the risk of childhood leukemia. Am J Epidemiol 2006;163:1091-1100.

34 Vineis P, Veglia F, Garte S, Malaveille C, Matullo G, Dunning A, Peluso M, Airoldi L, Overvad K, RaaschouNielsen O, Clavel-Chapelon F, Linseisen JP, Kaaks R, Boeing H, Trichopoulou A, Palli D, Crosignani P, Tumino R, Panico S, Bueno-De-Mesquita HB, Peeters PH, Lund E, Gonzalez CA, Martinez C, Dorronsoro M, Barricarte A, Navarro C, Quiros JR, Berglund G, Jarvholm B, Day NE, Key TJ, Saracci R, Riboli E, Autrup H: Genetic susceptibility according to three metabolic pathways in cancers of the lung and bladder and in myeloid leukemias in nonsmokers. Ann Oncol 2007;18:1230-1242. 